DOI: https://doi.org/10.24867/08EF08Micunovic

\title{
TOPLOTNA I MIKROSKOPSKA KARAKTERIZACIJA ŽARENIH FDM UZORAKA IZRAĐENIH OD PETG KOMPOZITA SA UGLJENIČNIM VLAKNIMA
}

\section{THERMAL AND SEM ANALYSIS OF ANNEALED FDM SAMPLES MADE FROM PETG COMPOSITE WITH CARBON FIBERS}

\author{
Miljana Mićunović, Fakultet tehničkih nauka, Novi Sad
}

\begin{abstract}
Oblast - GRAFIČKO INŽENJERSTVO I DIZAJN
Kratak sadržaj - U radu je korišćen komercijalno raspoloživi FDM materijal, ColorFabb XT-CF20, od kojeg su delovi izrađeni na FFF štampaču, Prusa I3 Mk2, a zatim je primenjeno termičko postprocesiranje, tj. žarenje. Dve epruvete su izrađene $3 D$ štampom, da bi potom jedna od njih bila podvrgnuta kontrolisanom procesu žarenja. Oba uzorka su zatim analizirana $u$ pogledu toplotnih i mikroskopskih karakteristika, u cilju posmatranja promena u temperaturi ostakljivanja (Tg), procentu kristaliničnosti $i$ mezostrukturi poprečnog preseka, koje su rezultat primenjenog žarenja. Rezultati pokazuju da žarenje može biti uspešno primenjeno na ovom materijalu, sa ciljem da se poboljšaju mehaničke karakteristike delova. Uočene mezostrukturne promene pokazale su da proces hlađenja žarenih uzoraka zahteva primenu niže, konstantne brzine hlađenja u cilju minimizacije geometrijskog izobličenja.
\end{abstract}

Ključne reči: $3 D$ štampa, FDM, termičko postprocesiranje, žarenje, kompozit.

Abstract - This study deals with the commercial FDM material, ColorFabb XT-CF20, its fabrication on a desktop FFF printer, Prusa I3 Mk2 and thermal postprocessing by annealing. Two sample specimens were fabricated by $3 D$ printing, while one of them was subjected to annealing process. The specimens were subsequently analyzed for their thermal and microscopic properties in order to observe the changes in glass transition temperature (Tg), crystallinity and mesostructural properties as the result of thermal post-processing, i.e., annealing. The results showed that annealing can be used with this material with the potential to improve its mechanical characteristics. The observed changes in mesostructure showed that the cooling process requires prolonged time in order to minimize geometrical deformations.

Key words: $3 D$ printing, FDM, thermal post-processing, annealing, composite.

\section{UVOD}

Kao vid termičkog postprocesiranja, žarenje se često primjenjuje $u$ eksperimentalnoj i proizvodnoj praksi. Žarenje polimera (eng. annealing) se može realizovati i u standardnim pećnicama za sušenje materijala, a odvija se na temperaturama koje su iznad temperature ostakljivanja za određeni polimer.

\section{NAPOMENA:}

Ovaj rad je proistekao iz master rada čiji mentor je bio dr Ognjan Lužanin, red. prof.
Pri tom, temperatura žarenja može da bude i nekoliko desetina stepeni iznad $\mathrm{Tg}$, a vreme zadržavanja u peći obično se kreće od 30 minuta do nekoliko sati, pri čemu se materijal zatim hladi u peći do sobne temperature. Specifična temperatura i vreme zadržavanja u peći, mogu se najbolje odrediti i optimizovati eksperimentalnim putem. S tim u vezi, u nastavku je dat kratak pregled novijih istraživanja u vezi sa žarenjem termoplastičnih polimera $u$ oblasti 3D štampe.

Vaezi i Jang [1] su istraživali uticaj ekstrudiranja PEEK filamenta korišćenjem povišenih temperatura, pri čemu je oblast primene bila biomedicina. Jedan od zaključaka se odnosio na to da raspodela temperature u radnom prostoru mašine može imati značajan uticaj na stepen kristaliničnosti izrađenih delova.

Takođe je primećeno da se kod štampanja masivnijih anatomskih modela kostiju, javljaju površinske zone sa različitim nijansama boje, što je posledica neuniformne brzine hlađenja materijala, usled čega se javljaju zone sa različitim procentima kristaliničnosti. Autori su koristili termičko postprocesiranje ovakvih delova, tj. žarenje, kako bi omogućili izjednačavanje procenta kristaliničnosti po celoj zapremini uzorka. Wah, Volčak i Vlodarčik [2] bavili su se fenomenom super hlađenja (super-cooling phenomenon) kod PLA delova izrađenih primenom FDM tehologije. Budući da je PLA nakon FDM izrade još uvek bila ispod maksimalnog mogućeg stepena kristaliničnosti za tu vrstu materijala, primenili su postprocesiranje uzoraka iznad temperature ostakljivanja PLA.

Uzorci su ostavljeni u peći, na temperaturama od $85^{\circ} \mathrm{C}$ i $95^{\circ} \mathrm{C}$, u trajanju od $10 \mathrm{~min}$ i $70 \mathrm{~min}$. Pokazalo se da je su uzorci na višoj temperaturi i pri dužem vremenu žarenja pokazali veći procenat kristaliničnosti, pri čemu je maksimalni postignuti procenat iznosio $25 \%$.

Benvud i ostali [3] ispitivali su mogućnosti za poboljšanje karakteristika delova izrađenih od PLA, tako što su varirali toplotne katakteristike procesa ekstrudiranja. Uzorci su pripremljeni variranjem niza tehnoloških parametara, uključujući temperaturu radne ploče, temperaturu ekstrudiranja, i ugao deponovanja materijala. Jedan deo uzoraka je podvrgnut i termičkom postprocesiranju na temperaturama iznad temeperature ostakljivanja PLA. Uzorci su žareni u peći u trajanju od $1 \mathrm{~h}$, jedna grupa na temperaturi od $80^{\circ} \mathrm{C}$, a druga na 100 ${ }^{\circ} \mathrm{C}$. Detaljnom termomehaničkom analizom dobijenih uzoraka došli su do zaključka da sadržaj kristalne faze ima odlučujuću ulogu na ključne karakteristike uzoraka, što je u najvećoj meri bilo izraženo kod uzoraka koji su termički postprocesirani. Ivi i ostali [4] su ispitivali uticaj 
termičkog postprocesiranja na PLA uzorke izrađene od komercijalno dostupnih filamenata PLA i PLA ojačane ugljeničnim vlaknima (PLA/CF). Uzorci od oba tipa materijala, izrađeni na FDM štampaču, bili su žareni na tri različite temperature, a zatim su podvrgnuti ispitivanju zatezne čvrstoće i mikrostrukture. Takođe je ispitivan uticaj kratkih vlakana na mehanička svojstva 3D štampane PLA, kao i uticaj žarenja na procenat kristaliničnosti. Uzorci su žareni u trajanju od 120 minuta, stavljanjem u predgrejanu peć na temperaturama od 85 , 115, i $145{ }^{\circ} \mathrm{C}$, odnosno, 30, 60, i $90{ }^{\circ} \mathrm{C}$ iznad Tg PLA. Pokazano je da proces žarenja utiče na porast kristaliničnosti kod obe grupe uzoraka, iako nije pokazan statistički značajan porast mehaničkih svojstava koji bi pratio porast kristaliničnosti.

Ispitivanjem zatezne čvrstoće konstatovano je da prisustvo kratkih ugljeničnih vlakana značajno doprinosi porastu modula elastičnosti ispitivanih uzoraka. Rengiseti i ostali [5] ispitivali su šest tipova filamenata. Ispitivani su PLA, ABS i PETG, kao tri bazična materijala i njhove varijante sa kratkim ugljeničnim vlaknima, CF-PLA, CFABS i CF-PETG. Svi uzorci predviđeni za žarenje, bili su izrađeni sa istim skupom tehnoloških parametara.

Bez obzira na tip materijala, uzorci su zagrevani na temperaturu koja je bila za $5^{\circ} \mathrm{C}$ iznad njihove temperature ostakljivanja (Tg). Uzorci su stavljani u hladnu peći i zatim su zagrevani na potrebnu temperaturu. Žarenje na zadatoj temperaturi trajalo je 60 minuta, nakon čega su uzorci ostajali u isključenoj peći sve do potpunog hlađenja. Za uzorke od PETG i CF-PETG, žarenje uzoraka je doprinelo vidljivom poboljšanju zatezne čvrstoće i Jungovog modula elastičnosti, ali je savojna čvrstoća bila snižena.

$\mathrm{Na}$ osnovu sažete analize literature koja se bavi poboljšanjem karakteristika polimernih FDM uzoraka, može se konstatovati da su autori koristili temperature žarenja koje su se, u zavisnosti od vrste polimera, kretale od 5 do 90 ${ }^{\circ} \mathrm{C}$ iznad temperature ostakljivanja $\left(\mathrm{T}_{\mathrm{g}}\right)$, dok su korišćeni vremenski intervali žarenja bili u rasponu od 10 do 130 minuta. Za eksperiment u ovom radu, izabrana je temperatura žarenja koja je $30{ }^{\circ} \mathrm{C}$ iznad temperature ostakljivanja kompozita, dok će vreme žarenja iznositi 45 minuta.

\section{MATERIJALI I METODE}

\subsection{Materijal ColorFabb XT CF20}

U radu su korišćene dve epruvete, dimenzija 70x20x3 $\mathrm{mm}$. Obe su izrađene u postupku FDM ekstrudiranja, na štampaču Prusa I3 Mk2, korišćenjem komercijalno dostupnog filamenta ColorFabb-XT CF20. Osnovu ovog materijala čini PETG polimer sa dodatkom ugljeničnih vlakana u iznosu od $20 \%$ od ukupne mase polimera. PETG - Poli Etilen Teraftalat sa dodatkom Glikolne grupe, jeste kopoliester koji spada u amorfne kopolimere.

Kada nije izložen opterećenjima, PETG pokazuje dobru otpornost na razblažene vodene rastvore mineralnih kiselina, baza, soli, i sapuna. PETG takođe dobro podnosi dejstvo alifatičkih ugljovodonika, alkohola, kao i različitih vrsta ulja. Sa druge strane, halogenovani ugljovodonici, ketoni male molekulske mase i aromatični ugljovodonici, razlažu PETG. Budući da PETG ne sadrži
UV inhibitor, ne preporučuje se dugotrajno korišćenje proizvoda od PETG u spoljašnjim uslovima. U tabeli $1 \mathrm{su}$ prikazane osnovne karakteristike materijala ColorFabbXT CF20, koje navodi proizvođač.

Tabela 1. Osnovne karakteristike ColorFabb-XT CF20 materijala [6].

\begin{tabular}{|l|c|c|c|}
\hline \multicolumn{1}{|c|}{ Svojstvo } & Jedinice & Vrednost & Standard \\
\hline Specifična gustina & $\mathrm{g} / \mathrm{cm} 3$ & 1.35 & ISO 1183 \\
\hline Apsorpcija vlage & $\%$ & - & - \\
\hline Zatezna čvrstoća & $\mathrm{MPa}$ & 76 & ISO 527 \\
\hline $\begin{array}{l}\text { Izduženje (\%) pri } \\
\text { zateznom lomu }\end{array}$ & $\%$ & 7.5 & ISO 527 \\
\hline Savojna čvrstoća & $\mathrm{MPa}$ & 110 & ISO 178 \\
\hline $\begin{array}{l}\text { Modul savojne } \\
\text { čvrstoće }\end{array}$ & $\mathrm{GPa}$ & 6.2 & ISO 178 \\
\hline $\begin{array}{l}\text { Udarna žilavost } \\
\text { (Izod, sa zarezom) }\end{array}$ & $\mathrm{kJ} / \mathrm{m}^{2}$ & 6 & ISO 180 \\
\hline $\begin{array}{l}\text { Udarna žilavost } \\
\text { (Izod, bez zareza) }\end{array}$ & $\mathrm{kJ} / \mathrm{m}^{2}$ & 60 & ISO 180 \\
\hline
\end{tabular}

\subsection{DSC i TGA analiza filamenta i delova}

Diferencijalna skenirajuća kalorimetrijska analiza (DSC) je urađena za filament i za termički postprocesirani uzorak. Za analizu je korišćen instrument NETCH, model 204F1 Phoenix. Ispitivanje karakterističnih toplotnih prelaza DSC uzoraka od termoplastičnog polimera vršeno je u intervalu temperatura od $25^{\circ} \mathrm{C}$ do $230^{\circ} \mathrm{C}$. Merenje je relizovao pri linearnim povećanju temperature koje se odvijalo brzinom od $10{ }^{\circ} \mathrm{C}$ u minuti (Ramp metodom). Prethodno je izvršena standardna kalibracija pomoću indijuma, čija je temperatura topljenja $157{ }^{\circ} \mathrm{C}$. Termogravimetrija (TGA) je urađena na uzorku koji je uzet sa filamenta, u cilju dobijanja temperature na kojoj nastupa degradacija materijala, tj. gubitak mase. Analiza je rađena u azotnoj atmosferi, do temperature od $600{ }^{\circ} \mathrm{C}$.

\section{3 Žarenje epruvete}

Šema instrumentacije koja je korišćena u toku termičkog postprocesiranja, tj. žarenja epruvete, prikazana je na sl. 1.

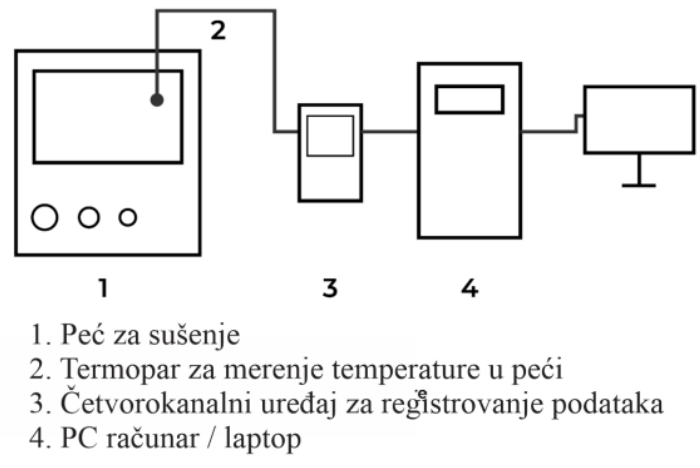

Slika 1. Šema povezivanja uređaja i instrumentacije korišćenih u postupku termičkog postprocesiranja

Za žarenje je korišćena standardna peć za sušenje (1). Temperatura u peći je merena uz pomoć termopara (2) koji je povezan sa data logerom - četvorokanalnim uređajem za merenje temperature (3). Data loger je USB vezom priključen na PC računar (4), gde su beleženi podaci o vremenu $\mathrm{i}$ temperaturi $\mathrm{u}$ toku celokupnog 
trajanja eksperimenta, od početka zagrevanja, do završenog hlađenja na sobnu temperaturu. Fotografija sa opisanom instrumentacijom i detaljima, prikazana je na slici 2.

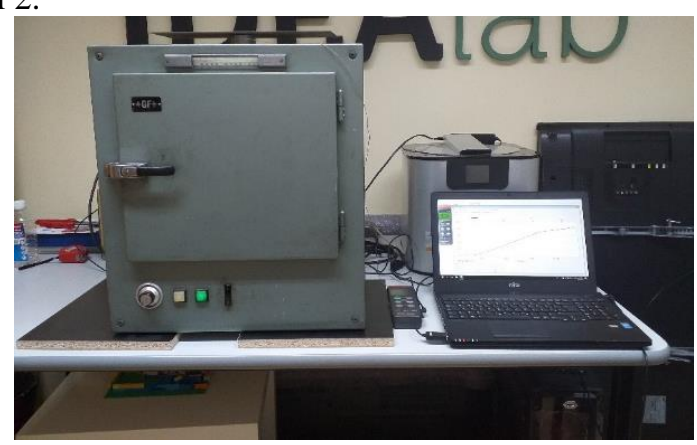

Slika 2. Snimak laboratorijske opreme, na kojem se vide peć, data loger i laptop računar

U toku termičkog postprocesiranja, epruveta je slobodno ležala na staklenoj vuni, dok u radnom prostoru peći nije bilo nikakve kontrole sadržaja atmosfere ili pritiska.

\section{REZULTATI ŽARENJA I TOPLOTNE ANALIZE}

\subsection{Rezultati žarenja epruvete}

Postprocesiranje epruvete u peći obuhvatilo je tri karakteristične faze:

- Zagrevanje peći na radnu temperaturu od $110^{\circ} \mathrm{C}$;

- Žarenje epruvete na radnoj temperaturi od $110^{\circ} \mathrm{C}, \mathrm{u}$ trajanju od $45 \mathrm{~min}$;

- Hlađenje epruvete u isključenoj peći, do sobne temperature.

Kretanje temperature i vremena, $u$ toku procesa termičkog postprocesiranja epruvete, prikazano je na vremenskotemperaturnom dijagramu.

Prvi dijagram (sl. 3) predstavlja kompletan proces žarenja i obuhvata zagrevanje, žarenje u trajanju od 45 minuta i hlađenje u peći, do sobne temperature. Treba primijetiti da je na drugom dijagramu, koji predstavlja samo žarenje uzorka (sl. 4), tokom $45 \mathrm{~min}$ temperatura oscilovala od $109^{\circ} \mathrm{C}$ do $111^{\circ} \mathrm{C}$. Uzimajući u obzir da je potrebna temperatura bila $110^{\circ} \mathrm{C}$, ove promjene su zanemarljive i nijesu uticale na rezultate eksperimenta.

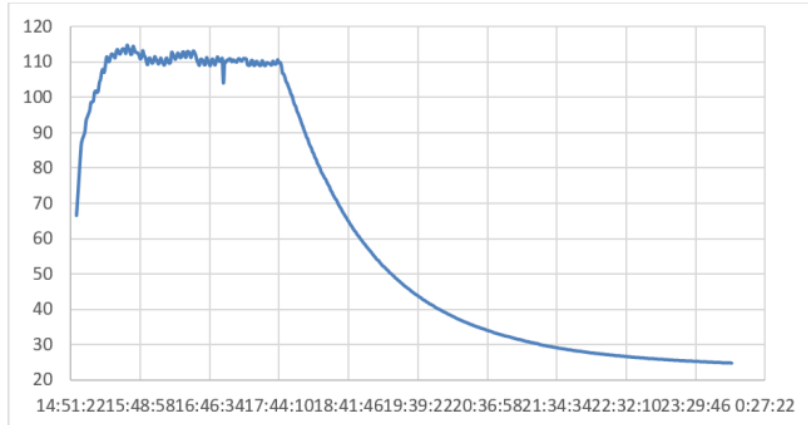

Slika 3. Dijagram zavisnosti temperature od vremena, za celokupan proces žarenja epruvete.

Zbog otvaranja vrata peći, prilikom ubacivanja uzorka, temperatura je malo opala, što se može zapaziti i na dijagramu. Međutim, temperatura se stabilizovala u roku od jednog minuta $\mathrm{i}$ tada je počelo mjerenje vremena žarenja. Po isteku 45 minuta, proces je završen, a peć isključena, kako bi se omogućilo hlađenje u zatvorenoj peći. Zbog nedostatka automatske kontrole hlađenja, proces nije tekao linearno, već sa promenljivim gradijentom (sl. 3), a brzina hlađenja je bila najveća $u$ toku prvog sata hlađenja $\left(45^{\circ} \mathrm{C} / \mathrm{h}\right)$.

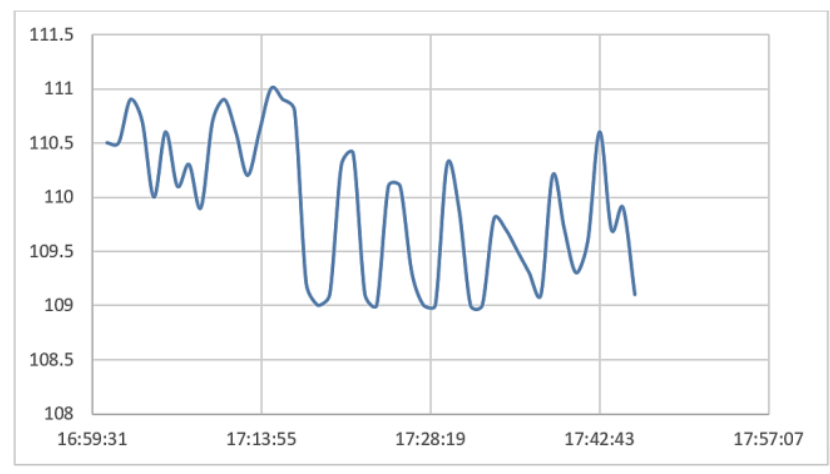

Slika 4. Detalj dijagrama zavisnosti temperature od vremena, koji prikazuje samo oscilovanje temperature $u$ toku procesa žarenja u trajanju od 45 minuta, na nominalnoj temperaturi od $110^{\circ} \mathrm{C}$.

\subsection{Rezultati DSC i TGA analize}

TGA kriva koja je rezultat termogravimetrijske analize, prikazana je na slici 5. Početak degradacije, tj. gubitka mase filamenta, zabeležen je na temperaturi od $370{ }^{\circ} \mathrm{C}$.

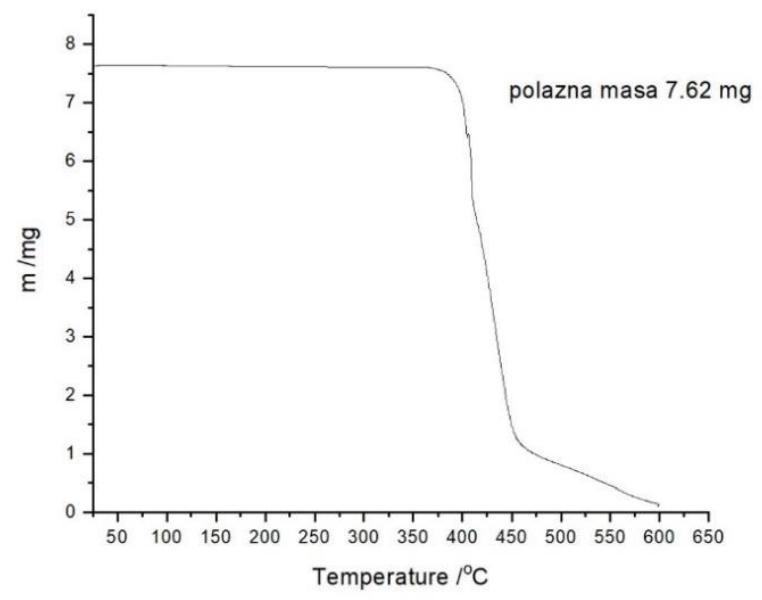

Slika 5. TGA kriva dobijena za uzorak koji je uzet sa filamenta ColorFabb-XT CF2O.

Na slici 6 je prikazana DSC kriva koja je rezultat analize uzorka uzetog od filamenta i sa nje se može vidjeti da se početak ostakljivanja odvija na temperaturi od $69.5^{\circ} \mathrm{C}$, dok se za temperaturu ostakljivanja usvaja temperatura od $75{ }^{\circ} \mathrm{C}$. Dobijena temperatura ostakljivanja je za $5{ }^{\circ} \mathrm{C}$ niža od deklarisane $\mathrm{T}_{\mathrm{g}}$, koju navodi proizvođač filamenta, ColorFabb. S obzirom da se radi o amorfnom materijalu, osim toplotnog prelaza koji je karakterističan za ostakljivanje, na preostalom delu DSC krive nisu vidljive nikakve promene koje su karakteristične za kristalinične materijale, tj. hladna kristalizacija i topljenje. Na osnovu ovoga se zaključuje da je reč o amorfnom materijalu. Kada je u pitanju DSC analiza uzorka koji je prošao termičko postprocesiranje (sl. 7), početak ostakljivanja je zabeležen na temperaturi od $74.5{ }^{\circ} \mathrm{C}$, dok je za temperaturu ostakljivanja usvojena temperatura od 77.9 ${ }^{\circ} \mathrm{C}$. Ova temperatura je za skoro 3 stepena Celzijusa viša 
od $\mathrm{T}_{\mathrm{g}}$ filamenta. Porast $\mathrm{T}_{\mathrm{g}}$ kao posledica žarenja jeste $\mathrm{u}$ skladu sa eksperimentalnim podacima koji se mogu naći u literaturi.

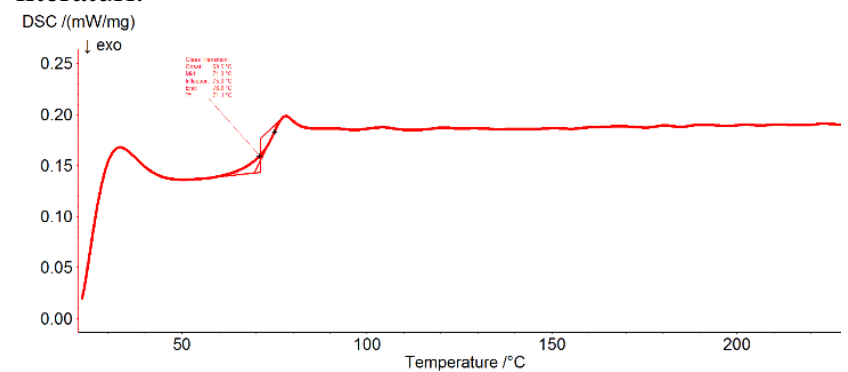

Slika 6. DSC kriva dobijena analizom uzorka koji je uzet sa fabrički isporučenog filamenta.

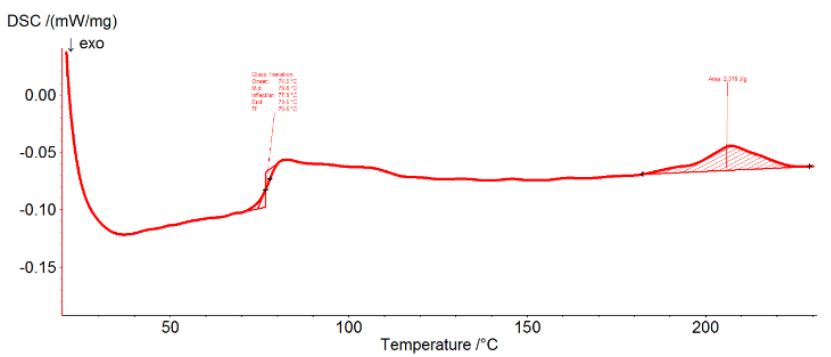

Slika 7. DSC kriva dobijena analizom uzorka koji se uzet sa žarene epruvete.

$\mathrm{S}$ obzirom da je epruveta provela 45 minuta na temperaturi koja je nešto preko $30{ }^{\circ} \mathrm{C}$ iznad njene temperature ostakljivanja, na temperaturi od $207{ }^{\circ} \mathrm{C}$ zabeleženo je topljenje kristalne faze, pri čemu izmerena entalpija iznosi $2.316 \mathrm{~J} / \mathrm{g}$.

\subsection{Rezultati mikroskopske analize}

Na snimku sa uvećanjem od 200x, vidljiva su tri izvora poroznosti (sl. 8). Priloženi snimak se odnosi na poprečni presek epruvete koja nije žarena, ali se diskusija koja sledi ne menja ni u slučaju žarene epruvete.

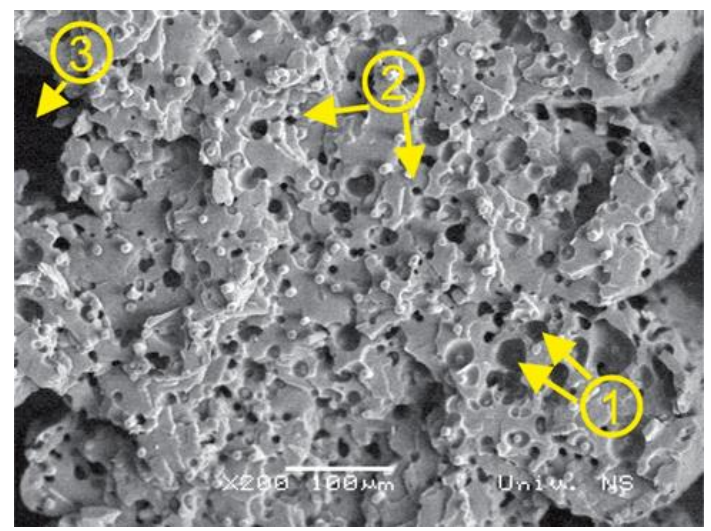

Slika 8. Uvećani poprečni presek, dobijen krio-lomom, sa obeleženim karakterističnim izvorima poroznosti - (1) gasni mehurovi, (2) šupljine iz kojih su iščupana kratka ugljenična vlakna, (3) nepopunjen prostor između dva bloka deponovanih staza.

Prisutni su ovalni mikrokrateri, koji su posledica pojave gasnih mehurova koji se javljaju prilikom ekstrudiranja (oznaka 1, sl. 8). Kružne rupice označene brojem 2, predstavljaju šupljine nastale odstranjivanjem ugljeničnih vlakana iz matrice osnovnog materijala. Za razliku od kontinualnih vlakana, zbog svoje male prosečne dužine, ispod $80 \mu \mathrm{m}$ ova vlakna često bivaju dislocirana $\mathrm{u}$ toku ekstrudiranja, tako da ne mogu da učestvuju u povećanju nosivosti poprečnog preseka. Treći tip poroznosti obeležen je brojem 3, i uočava se kao prazan prostor između susednih blokova deponovanih staza.

\section{ZAKLJUČCI}

Poređenjem DSC krivih koje su dobijene toplotnom analizom filamenta i epruvete koja je prošla termičko postprocesiranje, utvrđeno je da, kao rezultat žarenja, kod epruvete postoji entalpija topljenja kakva nije uočena na krivoj koja je dobijena za filament. Drugim rečima, čak i bez ikakvih iterativnih poboljšavanja izbora temperature žarenja, vremena zadržavanja na temperaturi žarenja i brzine hlađenja, dobijeno je izvesno povišenje kristaliničnosti $\mathrm{u}$ odnosu na potpuno amorfno, polazno stanje materijala. Međutim, ovo je samo prvi korak u eksperimentalnoj fazi i, u pogledu mogućih poboljšanja dobijenih rezultata, ispod su dati predlozi koji treba da predstavljaju smernice za dalji eksperimentalni rad. Postojeći eksperiment sa žarenjem, moguće je poboljšati uvođenjem kontrolisanog hlađenja. Umesto hlađenja kakvo smo imali $\mathrm{u}$ ovom eksperimentu, hlađenje bi trebalo da se odvija ujednačeno, tj. pad temperature po jednom času hlađenja, trebalo bi da se odvija sa konstantnim gradijentom. U tom smislu, pomenuti gradijent bi trebalo varirati od $5{ }^{\circ} \mathrm{C} / \mathrm{h}$ do $20{ }^{\circ} \mathrm{C} / \mathrm{h}$ i utvrditi vrednost koja daje najpogodniju kristalnu strukturu po završetku procesa. Takođe je potrebno izvršiti variranje temperature žarenja, budući da je moguće ići na temperature koje su iznad sadašnjih 110 ${ }^{\circ} \mathrm{C}$

\section{LITERATURA}

[1] Vaezi, M., Shoufeng, Y. 2015. "Extrusion-Based Additive Manufacturing of PEEK for Biomedical Applications" 2759 (October). https://doi.org/10.1080/17452759.2015.1097053

[2] Wach, R.A., Wolszczak, P., Adamus-Wlodarczyk. 2018.

"Enhancement of Mechanical Properties of FDM-PLA Parts via Thermal Annealing." Macromolecular Materials and Engineering, no. July: 1800169.

https://doi.org/10.1002/mame.201800169.

[3] Benwood, C., Anstey, A., Andrzejewski, J., Misra, M., Mohanty, A. 2018. "Improving the Impact Strength and Heat Resistance of 3D Printed Models: Structure, Property, and Processing Correlationships during Fused Deposition Modeling (FDM) of Poly(Lactic Acid).” ACS Omega 3 (4): 4400-4411. https://doi.org/10.1021/acsomega.8b00129.

[4] Ivey, M., Melenka, G.W., Carey, J.P., Ayranci, C., 2017. "Produced Using Additive Manufacturing Characterizing Short-Fiber-Reinforced Composites Produced Using Additive Manufacturing." Advanced Manufacturing: Polymer \& Composites Science 0340: 1-11. https://doi.org/10.1080/20550340.2017.1341125.

[5] Rangisetty, S., Peel, L.D. 2017. "The Effect of Infill Patterns and Annealing on Mechanical Properties of Additively Manufactured Thermoplastic Composites" Proceedings of the ASME 2017 Conference on Smart Materials, Adaptive Structures and Intelligent Systems SMASIS2017, September 18-20, 2017, Snowbird, UT, USA 1-12.

[6] ColorFabb. 2017. "Technical Datasheet - ColorFabb XT CF20" 31 (0): 53498607.

\section{Adrese autora za kontakt:}

MSc Miljana Mićunović miljanamicunovic@yahoo.com 